\title{
A PERSPECTIVA SÓCIO-HISTÓRICA DE LEONTIEV E A CRÍTICA À NATURALIZAÇÃO DA FORMAÇÃO DO SER HUMANO: A ADOLESCÊNCIA EM QUESTÃO
}

\author{
Ana Mercês Bahia BocK*
}

\begin{abstract}
RESUMO: A contribuição teórica de Leontiev convida-nos a superarmos a concepção naturalizante do ser humano no campo da psicologia. Esse avanço se torna possível se compreendermos o psiquismo humano como algo que se desenvolve por meio do processo de inserção do indivíduo na cultura e nas relações sociais. Este artigo se constitui numa análise crítica de publicações psicológicas sobre adolescência destinadas a pais e professores. Trabalhos que em psicologia focalizam o tema da adolescência tendem a ser especialmente caracterizados pela adoção da abordagem naturalizante. As conseqüências sociais dessa perspectiva são tomadas como critério para a exigência da crítica à própria perspectiva.
\end{abstract}

Palavras-chave: Naturalização. Adolescência. Leontiev. Psicologia sócio-histórica.

\section{LEONTYEV'S SOCIAL-HISTORICAL PERSPECTIVE \\ AND THE CRITICISM OF THE NATURALISTIC APPROACH TO HUMAN DEVELOPMENT WITH A FOCUS ON ADOLESCENCE}

ABSTRACT: Leontyev's theoretical approach invites us to go beyond the naturalistic conception of the human being in the field of psychology. This progress is possible if we understand the human mind as something that develops through the insertion process of the individual into culture and the social relations. This paper is a critical analysis of psychological publications on adolescence directed to parents and teachers. Writings in psychology that focus on adolescence tend to be greatly influenced by the naturalistic approach. The social consequences of this tendency point to the need for a critique.

Key words: Naturalization. Adolescence. Leontyev. Social-historical psychology.

Professora titular do Departamento de Psicologia Social da Faculdade de Psicologia da PUC-SP e membro do Grupo de Pesquisa "Adolescente: concepções e questões emergentes", do Programa de Pós-Graduação em Psicologia Social da mesma Instituição.E-mail: anabock@zaz.com.br 


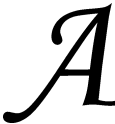

psicologia, no decorrer de seu desenvolvimento, vem apresentando teorias que naturalizam o ser humano. O estudo realizado por nós e concluído em 1997, publicado posteriormente (Bock, 1999), analisou o significado que os psicólogos, em São Paulo, atribuem ao fenômeno psicológico. Ficava evidente no estudo a naturalização do mundo psíquico e do próprio ser humano.

O homem, colocado na visão liberal, é pensado de forma descontextualizada, cabendo a ele a responsabilidade por seu crescimento e por sua psicológica. Um homem que "puxa pelos seus cabelos e sai do pântano por um esforço próprio". Um homem que é dotado de capacidades e possibilidades que lhe são inerentes, naturais. Um homem dotado de uma natureza humana que lhe garante, se desenvolvida adequadamente, ricas e variadas possibilidades. A sociedade é apenas o lócus de desenvolvimento do homem. É vista como algo que contribui ou impede o desenvolvimento dos aspectos naturais do homem. Cabe a cada um o esforço necessário para que a sociedade seja um espaço de incentivo ao seu desenvolvimento. As condições estão dadas, cabe a cada um aproveitá-las. (Bock, 1999)

Os psicólogos, ao falarem sobre o fenômeno psicológico, apresentam-no como se estivesse dado no ser humano tal fenômeno. Como se fosse algo da natureza humana, do qual somos dotados desde que nascemos. Não há qualquer preocupação em explicitar a gênese do psiquismo humano, pois este é tomado como algo natural. É impressionante o desinteresse dos psicólogos, apresentado no estudo, pelas relações sociais, pelas formas de produção da sobrevivência ou pela cultura.

A relação do indivíduo com a sociedade é uma relação praticamente inexistente nas respostas. As relaçôes apontadas como necessárias e importantes para o desenvolvimento do homem dizem respeito, fundamentalmente, às relações com os outros homens. Não são, no entanto, relações situadas no tempo histórico, em condiçōes determinadas de vida, permeadas de significações e linguagens específicas, com condições concretas de trabalho e formas de produção da sobrevivência. Não há a visão de um conjunto de homens compartilhando esses elementos históricos e sendo determinados por esses elementos. O termo social se refere, assim, apenas à existência de outros homens. (Bock, 1999)

Para nos contrapormos a esta perspectiva naturalizante na psicologia, adotamos a perspectiva sócio-histórica e para apresentar sua concepção histórica do ser humano vamos trazer as contribuições de 
A perspectiva sócio-histórica de Leontiev e a crítica à naturalização da formação...

Leontiev, em especial em seu texto "O homem e a cultura" (Leontiev, 1978, p. 261-284).

Leontiev apresenta nesse seu texto uma das versóes mais interessantes e sócio-históricas existentes sobre o desenvolvimento do que denominamos humano. Baseado em Engels, sustenta que o homem tem uma origem animal, mas

(...) ao mesmo tempo (...) o homem é profundamente distinto dos seus antepassados animais e (...) a hominização resultou da passagem à vida numa sociedade organizada na base do trabalho; (...) esta passagem modificou a sua natureza e marcou o início de um desenvolvimento que, diferentemente do desenvolvimento dos animais, estava e está submetido não às leis biológicas, mas a leis sócio-históricas. (Leontiev, 1978, p. 262)

O trabalho e a vida em sociedade são duas características da vida humana que vão permitir um salto de qualidade no desenvolvimento humano. O homem liberta-se de suas limitações biológicas para "inventar" a condição humana. Queremos com isso frisar a idéia de que as habilidades e os comportamentos humanos, a partir daquele momento, não estavam mais previstos pelo código genético. Por isso dizemos que o homem não estava mais submetido às leis biológicas e sim a leis sócio-históricas.

É Vigotski em seu texto "Internalização das funções psicológicas superiores" (1994) que vai apresentar o desenvolvimento destas capacidades, a partir da combinação entre o uso do instrumento (de trabalho) e do signo (atividade psicológica). Essa combinação vai permitir que o homem vá além do imediato, por meio de uma reconstrução interna de uma operação externa. Vigotski chamou a esse processo de internalização. Segundo o autor: "A internalização das atividades socialmente enraizadas e historicamente desenvolvidas constitui o aspecto característico da psicologia humana; é a base do salto quantitativo da psicologia animal para a psicologia humana" (Vigotski, 1994, p. 76).

É Leontiev que traz então a explicação que se esperava: se o homem se libertou de suas limitaçóes biológicas e criou o humano, como essas características passam de geração a geração se elas não podem fixar-se na herança genética? "Foi sob uma forma absolutamente particular, forma que só aparece com a sociedade humana: a dos fenômenos externos da cultura material e intelectual' (Leontiev, 1978, p. 265). 
É graças ao trabalho, entendido como emprego de energia humana para a transformação intencional da natureza, que os homens se põem nos objetos, humanizando-os. Pensemos em qualquer objeto que esteja em nosso mundo material ou intelectual. Eles são todos frutos da intervenção do homem.

Pela sua atividade, os homens não fazem, senão, adaptar-se à natureza. Eles modificam-na em função do desenvolvimento das suas necessidades. Criam os objetos que devem satisfazer as suas necessidades e igualmente os meios de produção desses objetos, dos instrumentos às máquinas mais complexas. Constroem habitações, produzem as suas roupas e outros bens materiais. Os progressos realizados na produção de bens materiais são acompanhados pelo desenvolvimento da cultura dos homens; o seu conhecimento do mundo circundante e deles mesmos enriquece-se, desenvolvem-se a ciência e a arte. (Leontiev, 1978, p. 265)

O homem, por meio de sua atividade sobre o mundo material, humaniza o mundo, isto é, ao mesmo tempo em que atua e trabalha, suas aptidões e conhecimentos vão se cristalizando, de certa maneira, nos seus produtos. Pensemos como a atividade de escrever, inventada pelo homem em um processo de milhares de anos, criou a habilidade de escrever e inventou, ao mesmo tempo, o lápis, a caneta, ou o pincel. Pensemos, agora, como esses objetos carregam em si a habilidade criada. Poderíamos fazer um exercício de imaginar os objetos e as máquinas existentes e verificarmos como carregam nossos movimentos em suas formas. Isso porque estão ali cristalizadas nossas habilidades. Cada pessoa, portanto, ao nascer encontra um

(...) mundo de objetos e de fenômenos criado pelas gerações precedentes. Ela apropria-se das riquezas desse mundo participando no trabalho, na produção e nas diversas formas de atividade social e desenvolvendo assim as aptidōes especificamente humanas que se cristalizaram, encarnaram nesse mundo. (Leontiev, 1978, p. 266)

Da mesma forma que aprendemos a lidar com o lápis, os utensílios domésticos, os objetos de arte etc., aprendemos a lidar com a linguagem. A linguagem também é um instrumento no qual foi cristalizada a habilidade do pensamento. Ao nos apropriarmos da linguagem, absorvemos com ela a capacidade de produzir um pensamento lógico abstrato. 
A perspectiva sócio-histórica de Leontiev e a crítica à naturalização da formação...

Para Leontiev não há aptidões e características especificamente humanas que tenham sido transmitidas por hereditariedade biológica; todas foram adquiridas

no decurso da vida por um processo de apropriação da cultura criada pelas gerações precedentes... Podemos dizer que cada indivíduo aprende a ser um homem. O que a natureza lhe dá quando nasce não lhe basta para viver em sociedade. É-lhe ainda preciso adquirir o que foi alcançado no decurso do desenvolvimento histórico da sociedade humana. (Leontiev, 1978, p. 267)

Os homens tornam-se, nesta abordagem, criadores de suas criaturas, pois são eles que constroem o mundo material que cristaliza suas habilidades desenvolvidas com a própria ação sobre o mundo e são eles que, ao atuarem novamente sobre o mundo para transformá-lo, internalizam as habilidades ali deixadas pelas gerações precedentes. Ao fazerem isso estarão deixando, para novas gerações, novas habilidades cristalizadas em novos instrumentos. $\mathrm{O}$ mundo em movimento, em processo contínuo de transformação, possibilita que o homem esteja também em permanente movimento e transformação. Esse processo, para Leontiev, é sempre ativo, do ponto de vista do homem, ou seja, para se apropriar dos

objetos ou dos fenômenos que são o produto do desenvolvimento histórico, é necessário desenvolver em relação a eles uma atividade que reproduza, pela sua forma, os traços essenciais da atividade encarnada, acumulada no objeto... A apropriação dos instrumentos implica, portanto, uma reorganização dos movimentos naturais instintivos do homem e a formação de faculdades motoras superiores. (Leontiev, 1978, p. 269)

Portanto, quando estamos falando de apropriação do instrumento e aprendizagem das habilidades, estamos nos referindo a uma apropriação das operações motoras que estão cristalizadas e incorporadas nos objetos. Por isso, dizemos que o processo é ativo para o homem, na medida em que é um processo de formação ativa de aptidões novas e de funções superiores que o hominizam.

Importante salientar que esse processo humano se dá em cada indivíduo da espécie que esteja vivendo em sociedade, mas é necessário compreendê-lo como um “(...) processo de reprodução, nas propriedades do indivíduo, das propriedades e aptidões historicamente formadas da espécie humana" (Leontiev, 1978, p. 270). 
O homem não nasce, portanto, dotado das aptidões e habilidades históricas da humanidade, pois elas foram conquistadas e criadas. $\mathrm{O}$ homem nasce candidato a essa humanidade, humanidade esta que está no mundo material, cristalizada nos objetos, nas palavras e nos fenômenos da vida humana. Aqui se invertem, por completo, as visões tradicionais da psicologia, que supõem uma humanidade natural do homem. As características humanas e o mundo psicológico que estavam tomados na psicologia como um a priori do homem, como algo de sua natureza humana, surgem agora como aquisições da humanidade e precisam ser resgatadas do mundo material para que o mundo psicológico se desenvolva, se humanize. Cabe aqui uma última citação de Leontiev:

Quanto mais progride a humanidade, mais rica é a prática sócio-histórica acumulada por ela, mais cresce o papel específico da educação e mais complexa é a sua tarefa. Razão por que toda a etapa nova no desenvolvimento da humanidade, bem como nos diferentes povos, apela forçosamente para uma nova etapa no desenvolvimento da educação: o tempo que a sociedade consagra à educação das geraçōes aumenta; criam-se estabelecimentos de ensino, a instrução toma formas especializadas, diferencia-se o trabalho do educador do professor; os programas de estudo enriquecem-se, os métodos pedagógicos aperfeiçoam-se, desenvolve-se a ciência pedagógica. Esta relação entre o progresso histórico e o progresso da educação é tão estreita que se pode sem risco de errar julgar o nível geral do desenvolvimento histórico da sociedade pelo nível de desenvolvimento do seu sistema educativo e inversamente. (Leontiev, 1978, p. 273)

Estas idéias são importantes para nossas reflexões sobre a adolescência porque: primeiro, não supõem um desenvolvimento natural, do qual a adolescência é conseqüência; segundo, a diversidade que se apresenta como riqueza humana é construída pela humanidade por meio de sua ação transformadora sobre o mundo e, sendo assim, nada que se apresente em nosso mundo nos deve ser estranho; terceiro, se a humanidade é transmitida e apropriada pelo indivíduo a partir de seu contato com os instrumentos da cultura, fica evidente que as diferenças sociais, que implicam diferentes graus de acesso a ela, serão produtoras de diferenças no desenvolvimento psicológico dos homens.

\section{A adolescência em questão}

Propusemo-nos neste texto a debater a questão da adolescência. Faremos isso a partir da apresentação de um estudo realizado por 
A perspectiva sócio-histórica de Leontiev e a crítica à naturalização da formação...

nós (Bock, 2002) sobre o conceito de adolescência presente em livros escritos com a finalidade de orientar pais e professores.

Nosso estudo foi realizado no segundo semestre de 2001 e primeiro de 2002 e integrou as pesquisas do Núcleo de Pesquisa sobre a Adolescência, do Programa de Pós-Graduação em Psicologia Social da PUC-SP, coordenado pelo professor Sergio Ozella. O estudo contou ainda com a participação de dois alunos da graduação em psicologia na PUC-SP, em Iniciação Científica: Mariana Hashimoto da Silva e João Carlos de Freitas Passos Jorge.

O estudo propôs-se a analisar as concepções de adolescência presentes em livros destinados a orientar pais e professores, buscando fazer uma leitura crítica dessas concepçôes e desvendando a perspectiva naturalizante que as tem caracterizado. E aqui relacionamos o estudo que vamos relatar com as concepções de Leontiev apresentadas até aqui. A adolescência tem sido, a nosso ver, definida, nesses livros e na psicologia em geral, como uma fase natural do desenvolvimento humano. Ela está pensada como se fizesse parte da natureza humana e como algo que desabrocha ao final da infância e antes da vida adulta. É apresentada com características que são tomadas como naturais e todos os indivíduos normais passam obrigatoriamente por essa fase do desenvolvimento. As concepçôes vão, portanto, na direção contrária das idéias de Leontiev. Nossa intenção é apresentar nosso estudo, que teve como referência as concepções sócio-históricas de Leontiev e Vigotski.

\section{O estudo}

O estudo partiu da definição de adolescência presente na psicologia, para depois analisar as concepções presentes nos livros. É este mesmo percurso que nos propomos a fazer aqui.

\section{A adolescência na psicologia}

A adolescência tem sido tomada, em quase toda a produção sobre o assunto, na psicologia, como uma fase natural do desenvolvimento, isto é, todos os seres humanos, na medida em que superam a infância, passam necessariamente por uma nova fase, intermediária à vida adulta, que é a adolescência. Inúmeros estudos dedicaram-se à caracterização dessa fase e a sociedade apropriou-se desses conhecimentos, 
tornando a adolescência algo familiar e esperado. Junto com os primeiros pêlos no corpo, com o crescimento repentino e o desenvolvimento das características sexuais, surgem as rebeldias, as insatisfações, a onipotência, as crises geracionais, enfim tudo aquilo que a psicologia, tão cuidadosamente, registrou e denominou de adolescência.

Torna-se necessário revisitar e rever o conceito porque, em suas concepções, a psicologia naturalizou a adolescência. Considerou-a uma fase natural do desenvolvimento, universalizou-a e ocultou, com esse processo, todo o processo social constitutivo da adolescência.

Foi Erickson (1976) quem institucionalizou a adolescência. Apresentou-a a partir do conceito de moratória e caracterizou-a como uma fase especial no processo de desenvolvimento, na qual a confusão de papéis, as dificuldades para estabelecer uma identidade própria a marcavam como "(...) um modo de vida entre a infância e a vida adulta” (Erickson, 1976, p. 128).

Erickson foi seguido de muitos autores. Na América Latina cabe destacar Aberastury \& Knobel (1989), os quais, com sua obra, tornaram-se referência para profissionais de várias áreas. Knobel introduziu a noção de "síndrome normal da adolescência", caracterizada por uma sintomatologia que inclui: "1) busca de si mesmo e da identidade; 2) tendência grupal; 3) necessidade de intelectualizar e fantasiar; 4) crises religiosas, que podem ir desde o ateísmo mais intransigente até o misticismo mais fervoroso; 5) deslocalização temporal, onde o pensamento adquire as características de pensamento primário; 6) evolução sexual manifesta, que vai do auto-erotismo até a heterossexualidade genital adulta; 7) atitude social reivindicatória com tendências anti ou associais de diversa intensidade; 8) contradições sucessivas em todas as manifestações da conduta, dominada pela ação, que constitui a forma de expressão conceitual mais típica deste período da vida; 9) uma separação progressiva dos pais; e 10) constantes flutuações de humor e do estado de ânimo" (Aberastury \& Knobel, 1989, p. 29).

Estava naturalizada a adolescência. Bastava a todos aguardarem que a adolescência um dia chegaria. Um caráter universal e abstrato foi dado a ela; inerente ao desenvolvimento humano, a adolescência não só foi naturalizada como foi tomada como uma fase difícil. Uma fase do desenvolvimento, semipatológica, que se apresenta carregada de conflitos "naturais". A cultura aparece apenas como molde da ex- 
A perspectiva sócio-histórica de Leontiev e a crítica à naturalização da formação...

pressão de uma adolescência natural, que em contrapartida sofre com a pressão exercida pela sociedade atual, a qual impõe a moratória ao adolescente pela dificuldade e demora em ingressar no mundo do trabalho. Nessas construções teóricas encontramos a visão de que o homem é dotado de uma natureza, dada a ele pela espécie, e, conforme cresce, desenvolve-se e relaciona-se com o meio, vai atualizando características que já estão lá, pois são de sua natureza. A adolescência pertence a esse conjunto de aspectos. Suas características são decorrentes do "amadurecer"; são hormônios jogados na circulação sanguínea e o desabrochar da sexualidade genital os fatores responsáveis pelo aparecimento da sintomatologia da adolescência normal.

Inúmeros estudos têm sido feitos sem que se apresente uma nova versão ou conceituação para a adolescência capaz de superar a visão naturalizante.

Estudos como os de Becker (1989) e Calligaris (2000) trouxeram elementos culturais para a leitura da adolescência, mas não superararam a visão abstrata do conceito. Becker (1989) propõe que olhemos a adolescência como "a passagem de uma atitude de simples espectador para uma outra ativa, questionadora. Que inclusive vai gerar revisão, autocrítica, transformação" (idem, p. 10). Adolescência, concebida como transformação, toma, da sociedade e da cultura, as formas para se expressar.

Calligaris (2000), partindo da adolescência como moratória, analisa de forma rica as dificuldades que os jovens vão encontrar na sociedade para se inserirem, nesta fase denominada adolescência. Uma fase que se instituiu na nossa cultura e que para o autor só se tornou problemática, merecendo destaque em nossos estudos, quando "o olhar adulto não reconheceu nelas os sinais da passagem para a vida adulta" (idem, ibid., p. 20). Calligaris avança na direção da superação do conceito abstrato afirmando: “(...) Numa sociedade em que os adultos fossem definidos por alguma competência específica, não haveria adolescentes, só candidatos e uma iniciação pela qual seria fácil decidir: sabe ou não sabe, é ou não é adulto. Como ninguém sabe direito o que é um homem ou uma mulher, ninguém sabe também o que é preciso para que um adolescente se torne adulto. O critério simples da maturação física é descartado. Falta uma lista estabelecida de provas rituais. Só sobram então a espera, a procrastinação e o enig- 
ma, que confrontam o adolescente - este condenado a uma moratória forçada de sua vida - com uma insegurança radical..." (idem, ibid., p. 21). O autor caminha investigando as dificuldades dos jovens em obterem da sociedade informaçôes que lhes possibilitem superar a moratória e finalmente conclui que o adolescente, na falta de definição "do que ser", torna-se um intérprete dos desejos adultos. “(...) o adolescente é levado inevitavelmente a descobrir a nostalgia adulta de transgressão, ou melhor, de resistência às exigências antilibertárias do mundo. Ele ouve, atrás dos pedidos dos adultos, um 'Faça o que eu desejo e não o que eu peço'. E atua em conseqüência' (idem, ibid., p. 28). Assim, Calligaris, a nosso ver, retoma uma concepção abstrata da adolescência: a fonte da adolescência está nos desejos adultos e não nas formas de vida.

Tanto em uma versão quanto em outra, a adolescência fica concebida como uma fase difícil, como uma fase problemática da vida, que deve ser superada. As características específicas da adolescência (se é que existem) são tomadas como negativas ou como bobagens da idade. $\mathrm{O}$ adolescente como parceiro social é visto com desconfiança e suas ações são tomadas como imaturas. O jovem fica desvalorizado na sociedade e o mundo adulto, em seu conservadorismo, reforçado.

A psicologia precisa, a nosso ver, superar essa perspectiva anistórica e abstrata, pois em nada tem contribuído para a valorização da adolescência e da juventude; em nada tem contribuído para a construção de políticas sociais voltadas para esses grupos que se constituam a partir de uma concepção positiva dessa fase da vida.

\section{O estudo}

O estudo desenvolveu-se a partir da análise de textos publicados sobre a adolescência, destinados a orientar pais e professores na "difícil" tarefa de educar esses jovens. Analisamos o conceito de adolescência presente nesses textos, por meio da sua sistematização em categorias que nos permitiram uma aproximação maior do discurso.

A escolha dos livros foi feita considerando-se: livros de alta vendagem; livros que contivessem o conceito e as indicações de conduta de como lidar com os adolescentes para que pudéssemos analisar as implicaçóes práticas das concepções; ter sido publicado nos últimos 
A perspectiva sócio-histórica de Leontiev e a crítica à naturalização da formação...

dez anos. Com estes critérios escolhemos quatro livros (Waldman, 1997; Tiba, 1996; Zagury, 1996 e 2001) que foram lidos na sua totalidade e um de seus capítulos escolhido para a análise. Aqui o critério foi o capítulo que contivesse o conceito de forma mais explícita e as decorrências em termos de sugestóes de conduta. Quatro categorias foram criadas, a partir da leitura, para sistematizar o conteúdo, a saber: 1) Descrição das características e do comportamento do jovem; 2) Descrição da relação dos jovens com adultos; 3) Explicação da adolescência: gênese; 4) Regras e orientações.

O texto foi, na sua íntegra, subdividido e organizado nestas categorias, que puderam ser lidas na sua verticalidade e depois na sua relação.

O trabalho com o discurso está todo baseado nas concepções de Vigotski (2001). "Para entender o discurso do outro, nunca é necessário entender apenas umas palavras; precisamos entender o seu pensamento" (Vigotski, 2001, p. 481). Tomamos a palavra como materialização do pensamento e assim nos propusemos a recuperar uma concepção de adolescência presente nos textos dos livros. Analisados os textos, sistematizamos os resultados obtidos com a análise, a partir das categorias apontadas.

\section{Características da adolescência}

A adolescência foi apresentada, nos quatro livros estudados, por meio de elementos, em geral, negativos. Negativos porque são características desvalorizadas na sociedade; negativos porque aparecem como incompletude, imaturidade, algo que ainda não acabou de acontecer e de se desenvolver. As características positivas que aparecem na descrição da adolescência são tomadas como algo "da fase", fruto da imaturidade. É definida em oposição com o adulto, o qual aparece como a meta deste desenvolvimento, como o estágio a ser atingido, como a etapa que apresenta as características que a adolescência ainda não possui. Adolescência é fase do desenvolvimento e encaminha-se para a vida adulta. Por isso a adolescência aparece como fase passageira.

Como fase do desenvolvimento, as características são universais e inevitáveis. Tomadas como fruto do desenvolvimento são também naturalizadas. É da natureza do homem e de seu desenvolvimento passar por uma fase, como a adolescência. As características dessa fase, 
tanto biológicas quanto psicológicas, são naturais. Rebeldia, desenvolvimento do corpo, instabilidade emocional, tendência à bagunça, hormônios, tendência à oposição, crescimento, desenvolvimento do raciocínio lógico, busca da identidade, busca de independência, enfim todas as características são equiparadas e tratadas da mesma forma, porque são da natureza humana.

\section{Relaçôes dos jovens com os adultos}

A relação é apresentada como uma relação difícil e conflituosa; uma luta, pois os jovens querem se libertar dos pais e estes não querem perder o controle dos filhos. Os critérios são diferentes, os gostos, as vontades, as regras, enfim, tudo é apresentado como sendo muito diferente entre pais e filhos. A diferença surge das características dos jovens que, por natureza, opõem-se ao que está estabelecido pelos pais. É característica da adolescência a oposição aos pais e ao mundo adulto.

\section{Explicação da adolescência: gênese}

É, a rigor, uma incógnita. Poucas referências são feitas à gênese da adolescência, não se buscando uma visão clara da gênese dos fenômenos. Como surgem essas características? Na verdade, não se tem nenhuma leitura sobre isso porque se crê que a adolescência é natural; é uma fase do desenvolvimento, não sendo necessário se falar da gênese; a ênfase recai sobre a descrição das características que estão em potencial na natureza humana e vão se atualizando conforme há desenvolvimento e crescimento. Assim, não há leitura social alguma. As relações com o mundo social e adulto aparecem somente como interferência; interferem, mas não constituem. As diferenças porventura existentes entre os adolescentes dão-se em razão das influências do meio que facilitam ou dificultam o desabrochar daquilo que é potencial.

\section{Orientaçôes e regras}

Os livros estão destinados a pais e professores, por isso a maior parte das orientações está dada aos adultos. Essas orientações são sempre na direção de pedir tolerância, compreensão e paciência. Os argumentos que justificam este pedido são: a adolescência é passageira, pois se constitui como uma fase do desenvolvimento; a adolescência, como algo necessário no crescimento, é incontrolável; e, por fim, os 
A perspectiva sócio-histórica de Leontiev e a crítica à naturalização da formação...

adultos são seres mais completos e prontos e, portanto, podem controlar a situação.

Pede-se aos adultos que controlem o medo de perder o filho e de perder o controle, mas não se discute a necessidade do controle (ela é naturalizada) nas relações pais e filhos.

Os adultos são incentivados ao controle, à autoridade, à imposição de regras, regras que são do mundo adulto. Mas são também incentivados ao amor, à compreensão, à tolerância, a manterem relações democráticas e a valorizarem positivamente o adolescente.

Todas as sugestóes partem da idéia de que a adolescência é natural. Portanto não há propostas ativas; recomenda-se apenas a aceitação e a paciência.

Concluindo, portanto, a adolescência, da forma apresentada nos textos, não tem gênese social. Nenhuma das suas características é constituída nas relações sociais e na cultura. Assim, ao se pensar a problemática da adolescência não se toma qualquer questão social como referência. A falta de políticas para a juventude em nossa sociedade, a desqualificação e inadequação das atividades escolares para a cultura jovem, o sentimento de apropriação que os pais têm, em nossa sociedade, com relação aos filhos, as contradições vividas, a distância entre o mundo adulto e o mundo jovem, a impossibilidade de autonomia financeira dos jovens que ou não trabalham ou sustentam a família, nenhuma destas questóes é tomada como elemento importante para compreender a forma como se apresenta a adolescência em nossa sociedade. As relações familiares são as únicas que aparecem nos textos e são fator de influência sobre a adolescência, mas não a constituem.

Outra questão importante é que o jovem, apresentado nos textos, é das camadas de médio ou alto poder aquisitivo. Não há, no entanto, qualquer referência a isso. $\mathrm{O}$ adolescente está tomado como universal, quando são evidentes as diferenças entre os grupos das diferentes classes sociais, em razão de diferentes formas de inserção social. As relações com os adultos são tomadas como conflituosas. Os adolescentes são responsabilizados pelas tensões. Utilizam-se termos como "luta" para fazer referência a essas relações. Com isso, deixa-se de incentivar relações de parceria social entre pais e filhos. Os pais recebem milhares de orientações que devem seguir para aliviar as tensões na família. Cabe a eles salvar as relaçôes. Ficam sobrecarregados 
de responsabilidades quando poderiam ver seus filhos adolescentes como parceiros, os quais, como qualquer pessoa, inclusive os próprios pais, têm, em cada momento da vida, projetos, necessidades e possibilidades que são delineadas pela cultura.

Nossa cultura valoriza o adulto produtivo. Desvaloriza todas as outras fases da vida: a infância, a velhice e a adolescência, tomadas como fases improdutivas para a sociedade, por isso desvalorizadas. A visão naturalizadora reforça estes valores, ao tomar o desenvolvimento como referência.

A psicologia não pode mais manter-se divulgando e reforçando estas visões, pois não contribui para a construção de políticas sociais adequadas para a juventude; não ajuda a construir projetos educacionais adequados para manter os jovens na escola, não ajuda a inserir os jovens nos grupos e nas instituiçôes que têm como vocação o debate sobre a juventude. Enfim, a visão naturalizante da adolescência é mais que uma visão a qual acoberta as determinações sociais; é uma visão que impede a construção de uma política social adequada para que os jovens possam inserir-se na sociedade como parceiros sociais fortes, criativos, cheios de projetos de futuro.

Pensar a juventude como uma manifestação da natureza humana é desvalorizá-la e condená-la à identificação com modelos vazios em termos de inserção na sociedade. É preciso superar estas concepções.

\section{A adolescência na teoria sócio-histórica}

Para darmos continuidade a nossa reflexão, gostaríamos de voltar ao diálogo com Leontiev e apontar, seguindo suas concepções sócio-históricas, um novo conceito para a adolescência.

A adolescência não é vista aqui como uma fase natural do desenvolvimento, como uma etapa natural entre a vida adulta e a infância. A adolescência é vista como uma construção social que tem suas repercussōes na subjetividade e no desenvolvimento do homem moderno e não como um período natural do desenvolvimento. É um momento significado, interpretado e construído pelos homens. Estão associadas a ela marcas do desenvolvimento do corpo. Essas marcas constituem também a adolescência como fenômeno social, mas o fato de existirem como marcas do corpo não deve fazer da adolescência um fato natural. 
A perspectiva sócio-histórica de Leontiev e a crítica à naturalização da formação...

Há muitas outras características que constituem a adolescência; além disso, as marcas corporais são significadas socialmente, não sendo tomadas no conceito de adolescência em si, como características do corpo e, portanto, naturais. Exemplo disso são os seios na menina e a força muscular nos meninos. Sabemos que os seios e o desenvolvimento da massa muscular acontecem na mesma fase da adolescência, mas a menina que tem seus seios se desenvolvendo não os vê, sente e significa como possibilidade de amamentar seus filhos no futuro, o que seria vêlos como naturais. Com certeza, em algum tempo ou cultura, isso já foi assim. Hoje, os seios tornam as meninas sedutoras e sensuais. Esse é o significado atribuído em nosso tempo. A força muscular dos meninos já foi significada como possibilidade de trabalhar, guerrear e caçar. Hoje é beleza, sensualidade e masculinidade.

Da mesma forma, o jovem não é algo "por natureza". Como parceiro social está ali, com suas características, que são interpretadas nessas relações; tem, então, o modelo para sua construção pessoal. Construídas as significações sociais, os jovens têm então a referência para a construção de sua identidade e os elementos para a conversão do social em individual.

A abordagem sócio-histórica, ao estudar a adolescência, não faz a pergunta "o que é a adolescência”, mas "como se constituiu historicamente este período do desenvolvimento". Isso porque, para essa abordagem, só é possível compreender qualquer fato a partir da sua inserção na totalidade, na qual esse fato foi produzido, totalidade essa que o constitui e lhe dá sentido. Responder o que é a adolescência implica buscar compreender sua gênese histórica e seu desenvolvimento.

A adolescência foi criada pelo homem. Fatos sociais vão surgindo nas relações sociais e na vida material dos homens; vai se destacando como um fenômeno social e vai apresentando suas repercussões psicológicas; vai sendo construído um significado social para esses fatos que vão acontecendo e, em um processo histórico, vai surgindo na sociedade moderna, ocidental, a adolescência. Construída como fato social e como significado, a adolescência torna-se uma possibilidade para os jovens (e para os não-jovens), uma forma de identidade social. Para compreender a adolescência é preciso, então, que retomemos seu processo social, para depois compreendê-la na forma como acontece para os jovens.

Adélia Clímaco (1991) traz em seus estudos vários fatores sociais - econômicos e culturais - que nos possibilitam compreender como sur- 
giu a adolescência. Retomaremos aqui esses fatores. A sociedade moderna, com suas revoluções industriais, gerou grandes modificações nas formas de vida. Com as revoluções industriais, o trabalho sofisticou-se, do ponto de vista tecnológico, e passou a exigir um tempo prolongado de formação, adquirida na escola, reunindo em um mesmo espaço os jovens e afastando-os do trabalho por algum tempo. Além disso, o desemprego crônico/estrutural da sociedade capitalista trouxe a exigência de retardar o ingresso dos jovens no mercado e aumentar os requisitos para esse ingresso, o que era respondido pelo aumento do tempo na escola.

A ciência, em contrapartida, resolveu muitos problemas do homem e ele teve a sua vida prolongada, o que trouxe desafios para a sociedade, em termos de mercado de trabalho e formas de sobrevivência.

Estavam dadas as condições para que se mantivessem as crianças mais tempo sob a tutela dos pais, sem ingressar no mercado de trabalho. Mantê-las na escola foi a solução. A extensão do período escolar e o conseqüente distanciamento dos pais e da família, além da aproximação de um grupo de iguais, foram as conseqüências destas exigências sociais. A sociedade então assiste à criação de um novo grupo social com padrão coletivo de comportamento - a juventude/adolescência.

A adolescência refere-se, assim, a esse período de latência social constituída a partir da sociedade capitalista, gerada por questóes de ingresso no mercado de trabalho e extensão do período escolar, da necessidade do preparo técnico.

Essas questões sociais e históricas vão constituindo uma fase de afastamento do trabalho e o preparo para a vida adulta. As marcas do corpo, as possibilidades na relação com os adultos vão sendo pinçadas para a construção das significações.

Podemos pensar que, a partir dessa nova situação social descrita por Clímaco, os jovens passaram a estar colocados em uma nova condição: o jovem, apesar de possuir todas as condições cognitivas, afetivas e fisiológicas para participar do mundo adulto, estava desautorizado a isso, devendo permanecer em um compasso de espera para esse ingresso; vai ficando distante do mundo do trabalho e, com isso, vai ficando distante das possibilidades de obter autonomia e condiçóes de sustento. Vai aumentando o vínculo de dependência do adulto, apesar de já possuir todas as condiçóes para estar na sociedade de outro modo. Essa contradição vivida pelos jovens foi responsável pelo desenvolvimento das características que refletem a nova condição social na qual se en- 
A perspectiva sócio-histórica de Leontiev e a crítica à naturalização da formação...

contram. Quais características são essas? Aquelas descritas pela psicologia, mas que agora tomam um outro sentido, pois não são naturais; são construídas nas relações sociais.

As condições sociais nas quais se encontram os jovens são claríssimas como fonte mobilizadora e geradora da chamada "adolescência”. A moratória na qual se encontram os jovens não é um período necessário do seu desenvolvimento e, sim, um período no qual o mundo adulto considerou necessário colocar seus jovens para poderem os adultos estar mais tempo no mercado de trabalho e para poderem os jovens serem mais bem preparados para responderem às exigências do novo mundo do trabalho tecnológico.

As "marcas" da juventude e seus significados modificaram-se no tempo e nas diversas civilizações: força física, cortesia e amor, guerra e caça, jogos, proezas, responsabilidades, transgressões; 20 anos ou 30 anos; uma etapa curta ou longa de passagem para a vida adulta, a adolescência não foi a mesma coisa sempre.

Importante registrar que, na medida em que esse fato social da adolescência vai se configurando, tomando contornos mais claros, a sociedade como um todo vai registrando e significando esse momento. A ciência estuda-a, conceitua-a, expressa-a em livros e descreve suas características (tomadas como se fossem naturais da idade). A sociedade vai reconhecendo então uma fase do desenvolvimento de seus filhos e jovens; vai atribuindo significados; vai esperando de seus filhos e jovens algumas condutas. A adolescência instala-se de forma inequívoca na sociedade. Os jovens que não possuíam referências claras para seus comportamentos vão, agora, utilizando essas características como fonte adequada de suas identidades: são agora adolescentes.

Não há nada de patológico; não há nada de natural. A adolescência é social e histórica. Pode existir hoje e não existir mais amanhã, em uma nova formação social; pode existir aqui e não existir ali; pode existir mais evidenciada em um determinado grupo social, em uma mesma sociedade (aquele grupo que fica mais afastado do trabalho), e não tão clara em outros grupos (os que se engajam no trabalho desde cedo e adquirem autonomia financeira mais cedo). Não há uma adolescência, como possibilidade de ser; há uma adolescência como significado social, mas suas possibilidades de expressão são muitas.

Recebido em novembro de 2003 e aprovado em março de 2004. 
Referências bibliográficas

ABERASTURY, A.; KNOBEL, M. Adolescência normal. Porto Alegre: Artes Médicas, 1989.

BECKER, D. O que é a adolescência. São Paulo: Brasiliense, 1989.

BOCK, A.M.B. Aventuras do Barão de Munchhausen na psicologia. São Paulo: Cortez; EDUC, 1999.

BOCK, A.M.B. Adolescência: uma construção social; um olhar crítico sobre o conceito em livros destinados a pais e professores. Relatório de pesquisa de doutorado, São Paulo, 2002. Mimeografado.

CALligaris, C. A adolescência. São Paulo: Publifolha, 2000.

CLÍMACO, A.A.S. Repensando as concep̧̧ões de adolescência. 1991. Tese (Doutorado) - Pontifícia Universidade Católica de São Paulo, São Paulo.

ERICKSON, E. Identidade, juventude e crise. Rio de Janeiro: Zahar, 1976.

LEONTIEV, A. O desenvolvimento do psiquismo. Lisboa: Livros Horizonte, 1978.

TIBA, I. Disciplina: limite na medida certa. São Paulo: Gente, 1996.

VIGOTSKI, L.S. A formação social da mente. 5. ed. São Paulo: Martins Fontes, 1994.

WALDMAN, L. E agora?: tenho um filho adolescente. São Paulo: Mercuryo, 1997.

ZAGURY, T. $O$ adolescente por ele mesmo: orientação para pais e educadores. Rio de Janeiro: Record, 1996.

ZAGURY, T. Limites sem trauma: construindo cidadãos. 12. ed. Rio de Janeiro: Record, 2001. 